\title{
LOS MEDIOS DE COMUNICACIÓN SOCIAL EN PANAMÁ: ANTECEDENTES, SITUACIÓN Y PERSPECTIVA HACIA EL NUEVO MILENIO. UN ANALISIS CRÍTICO
}

\author{
THE SOCIAL MEDIA IN PANAMA: \\ BACKGROUND, STATUS AND PROSPECTS FOR THE NEW \\ MILLENNIUM. A CRITICAL ANALYSIS
}

\section{AUTORA}

Vielka Vásquez de Ávila

Ex - decana de la Facultad de Ciencias de la Comunicación Social. Universidad de Panamá. (Panamá). vielkavasquez@hotmail.com

\section{RESUMEN}

En Panamá, como ocurre en el resto de países de América Latina, los medios de comunicación social se concentran en las zonas urbanas, marginando las zonas rurales, en este caso, por lo tanto, la mayor concentración se sitúa en la provincia de Panamá, la más desarrollada. Los medios de comunicación en Panamá se ven afectados por el desequilibrio socioeconómico. La información en este país es vertical y lineal, con un emisor manipulador y autoritario y un receptor pasivo, sin existir apenas intercambio de experiencias entre ambos. Existe una gran dependencia, y por lo tanto influencia, de Estados Unidos en el campo de las comunicaciones.

\section{PALABRAS CLAVE}

Panamá - EEUU - Medios de comunicación - Dependencia 


\section{ABSTRACT}

In Panama, as in the rest of Latin America, the media are concentrated in urban areas, marginalizing rural areas, in this case, therefore, the greatest concentration is in the province of Panama, the most developed. The media in Panama are affected by socio-economic imbalance. The information in this country is vertical and linear with a manipulative authoritarian issuer and a passive recipient, with no little exchange of experience between them. There is a great unit, and therefore influence, the United States in the field of communications.

\section{KEY WORDS}

Panama - USA - Media - Dependence

\section{ÍNDICE}

1. Medios de comunicación social.

1. $\quad 1.1$ La prensa

2. 1.2 La radio

3. 1.3 La televisión

4. $1.4 \mathrm{El}$ cine

2. La radio

3. Medios impresos

4. La televisión

6. El cine

5. Sistema de televisión por cable. 
"El ser humano necesita informarse para ajustarse a vivir. No se le puede informar mal o desinformar por negocio o por ningún otro motivo, porque si al hombre no se le informa bien para que viva positivamente en su planeta, ya ha demostrado que tiene más poder que los dinosaurios para autodestruirse y desaparecer"

Inicio esta ponencia con estas sabias palabras del ya fallecido Prof. Luis González, quién fuera nuestro maestro y luego colega. Estas mismas me sirven para reflexionar de partida sobre la función de los medios de comunicación social en una sociedad libre y democrática como la del Panamá de hoy.

Al mismo tiempo deseo citar al autor Ignacio de la Mota quién, en su obra La funcion social de la informacion, señala con mucho acierto que es función de los medios servir de elemento mediador entre el poder y los ciudadanos e integrar en el sistema de libertades a todas las capas sociales e individuos; de allí su función política, es decir, su contribución a la vida política de la sociedad de la que forma parte.

En este sentido, los medios van a transmitir al sistema político los insumos provenientes del sistema social, lo que le permitirá cambiar sus estructuras $y$, posiblemente, la situación ambiental. Estos medios también pueden transmitir al ambiente social las decisiones del sistema político. Por tanto, los medios actúan como mediadores políticos, pero también actúan como mediadores de ideas, de cultura, de valores, en fin como mediadores sociales entre el sistema sociocultural y el individuo. De allí, señalamos que los medios contribuyen a crear una conciencia nacional, que no es otra cosa que el resultado de la unión de valores ideológicos, históricos, emotivos y políticos que tiene cada miembro de una comunidad. 
Para Ángel Benito, los medios tienen una función integradora, contribuyen a la apertura de la participación y se constituyen en el mejor medio para romper barreras y superar toda clase de prejuicios sociales.

Para Jorge Xifra, los medios de comunicación ayudan a aliviar al individuo de las situaciones patológicas que son fruto de la masificación y de la alienación. Todas estas sabias consideraciones nos llevan a plantearnos los medios como canales técnicos con objetivos diversos pero con un solo propósito: mejorar de una u otra forma las condiciones de vida de hombres y mujeres.

5.

\section{Medios de comunicación social.}

Los medios de comunicación social, según su clasificación más rudimentaria, son:

\subsection{La prensa}

El medio de comunicación tradicional por excelencia y el más antiguo de los masivos. Comprende los periódicos diarios, así como los semanarios y revistas de información general. Es el preferido por las elites tanto para informarse como para informar. Su mensaje es exclusivamente visual y utiliza sólo la palabra escrita y la imagen impresa.

\subsection{La radio}

Con el advenimiento de este medio se elevó la comunicación oral a un nivel de información de masas, con una serie de ventajas sobre la prensa; entre ellas, la de una mayor simultaneidad en el mensaje, así como el estar al alcance de analfabetos. 


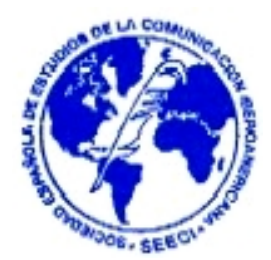

\subsection{La televisión}

Este medio está basado en la transmisión a distancia de imagen en movimientos y sonido. Este permite a los seres humanos ser testigos simultáneos de todos los hechos que se producen en lugares recónditos y lejanos.

\subsection{El cine}

Segundo medio de comunicación social y que se basa en el principio de los fotogramas fijos a una velocidad determinada, que dan la sensación de movimiento real.

América Latina refleja un cuadro infraestructural, en materia de medios de comunicación, verdaderamente interesante. Hace algunos años CIESPAL publicó un estudio en donde se analiza la alta concentración de los medios de comunicación social en zonas urbanas y la cada vez más manifiesta marginalidad de zonas rurales y semi urbanas, hacia los programas de desarrollo.

Al igual que muchos de los países del área latinoamericana, Panamá acusa una alta concentración de los tres medios tradicionales de comunicación en las zonas urbanas, en este caso la provincia de Panamá. Se observa, por tanto, marginalidad y bajo acceso de otros sectores de población hacía los medios masivos de comunicación.

Esta realidad nos lleva a admitir que los instrumentos de comunicación están afectados por las características del sistema social y sus necesidades.

Panamá es un país pequeño ubicado en el centro del continente americano, tiene una extensión de cerca de 76,000 kilómetros cuadrados y alrededor de 2.8 millones de habitantes según cifras de población recientes y se calcula que para el próximo 
censo (año 2000) su población llegara a los tres millones. Su capital es la Ciudad de Panamá en donde se concentra la mayor cantidad de población. Sus nueve provincias son Panamá, Colón, Chiriqui, Darién, Los Santos, Herrera, Cocle, Veraguas, Bocas del Toro y una comarca indígena, San Blas.

Según estudios e informes de organizaciones especializadas, en la actualidad, América Latina enfrenta índices de extrema pobreza realmente alarmantes, con grandes abismos en la distribución de la riqueza y galopante ritmo de crecimiento del desempleo y sub empleo. Panamá, no escapa de esta situación, ni los medios de comunicación panameños dejan de estar afectados por este desbalance socioeconómico el cual, como es natural, crea, entre quienes controlan los propios medios de comunicación, cuadros de intereses comunes, cuales son el ejercicio de influencias en los sectores de poder económico.

Alrededor de la mitad de las emisoras de radio se concentran en la ciudad de Panamá. Por otra parte, tanto los canales de televisión, así como los periódicos más importantes se encuentran también en la ciudad capital. Es clara la correlación existente entre la presión económica de la actividad publicitaria, el poder adquisitivo y la concentración de medios de comunicación. Ello nos conduce igualmente a concluir que buena parte de la población panameña se convierte en receptora pasiva de una gran cantidad de mensajes que no satisface sus expectativas, ni intereses.

Para Rafael B. Ayala, catedrático panameño en comunicación,

"observar el proceso de comunicación como un mero sistema de información, es sustraer elementos valiosos que se encuentran implícitos en el verdadero acto de la comunicación". 
Añade que

"el actual sistema panameño, no ha dejado de encuadrarse en los viejos moldes de la información vertical y lineal, en donde existe predominantemente un emisor prepotente, manipulador $y$ autoritario, frente a un gran público de receptores pasivos en donde el fenómeno múltiple de intercambio de experiencias es casi nulo".

\section{La radio}

En el aspecto de la radiodifusión, se calcula que en todo el territorio panameño existen 147 estaciones de radio AM y FM, sin embargo, de ellas una gran cantidad, su operación se circunscriben a la transmisión de programación ligera y superficial. Los estudios realizados con respecto a la elevada infraestructura radial y su relación con la fuente de información indican que, a pesar de que existe un alto número de emisoras, se acusa un deficiente sistema de comunicación e información ya que los temas y programas de la mayoría de las radioemisoras contradicen los fundamentos sociales enmarcados en la constitución política y, específicamente, lo referente a los medios de comunicación social.

Vale la pena resaltar ciertas consideraciones históricas que avalarán algunos aspectos de la radio en Panamá. En este sentido deseamos citar algunas consideraciones de Rafael Ayala en su libro Teoría y Realidad de la Comunicación en Panamá. Señala el mencionado catedrático que

"la trayectoria normativa de la radio parte en principio de nuestra relación con los Estados Unidos y la configuración de la infraestructura canalera (canal y bases militares). El tratado Hay Buneau Varilla condicionó todos los aspectos inherentes a esta materia a la supervisión unilateral de Estados Unidos" 


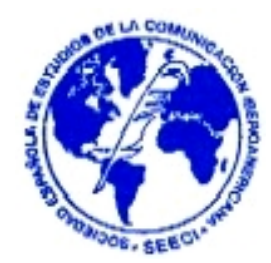

Posteriormente, Panamá logró asumir en forma escalonada su jurisdicción, hasta ejercer el control pleno de su espectro radio eléctrico. No obstante, el ejército de Estados Unidos mantiene aún y hasta el 31 de diciembre de este año 1999, la Cadena del Comando Sur S.C.N. (Southern Command Network) de radio y televisión, controlando la frecuencia 790 en la Provincia de Panamá y la 1420 en la Provincia de Colón, ambas en amplitud modulada, así como dos frecuencias moduladas, 91.5 y 98.3 para las ciudades de Panamá y Colón, respectivamente. En el aspecto televisivo la S.C.N. , hasta esa misma fecha el 31 de diciembre de este año, tiene bajo control el canal 8 en la ciudad de Panamá, específicamente para el área del Canal, y el 10 para el área de Cristóbal en la ciudad de Colón. Ambos canales de televisión transmiten en la banda de muy alta frecuencia VHF.

Haciendo un examen de las diversas reglamentaciones que se han hecho desde 1940 hasta la fecha, encontramos que aproximadamente cada 10 años se hacen reformas y adiciones. En 1962 se dicta el Decreto ejecutivo NO.155 del 28 de mayo. Este señala que son imprescindibles los servicios de radiodifusión para el desarrollo y progreso del país, de acuerdo con las exigencias de la vida moderna. Sin embargo a pesar de que en su etapa fue necesario y conveniente la reglamentación, ha sido hasta este año cuando se aprueba la ley 24 del 30 de junio que norma todo lo relativo a concesiones, frecuencias para tener concesiones tanto de radio como televisión. Igualmente, se norman algunos elementos de publicidad y bandas $A$ y $B$ de equipo de radio y televisión.

La estructura de una estación de radio comercial hay que analizarla desde tres aspectos esenciales: económico, humano y técnico. Estos tres elementos están íntimamente ligados con el contenido programático de una estación determinada. El explosivo aumento de radioemisoras en Panamá ha producido un desajuste y desbalance en estos aspectos, mermando considerablemente la calidad de la programación de una gran cantidad de estaciones de radio comercial. 
La televisión auténticamente panameña, abordó a nuestro país en 1960. Para ese momento existía el Canal 8 de SCN de las fuerzas armadas de Estados Unidos con programación en inglés y que funcionaba desde una de las bases militares norteamericanas. El advenimiento de la televisión en Panamá causó, como en muchos países, una migración de personal de la radio, afectando sustancialmente a ese medio de comunicación. Artistas y libretistas fueron integrados a la televisión la cual se inicia con una abundante programación en vivo. La radio se sobrepone a ese colapso como logra hacerlo en la mayoría de los países del mundo. Digno es de anotar que la radiodifusión nacional en Panamá ha ido creciendo en forma entusiasta, pero con objetivos no definidos. Nuestro punto de vista se sustenta en la necesidad que existe de revisar la actual disposición que reglamenta los servicios de radio en Panamá.

En Panamá, cualquier ciudadano que desee contratar un espacio radial puede hacerlo sin ningún tipo de limitaciones. En igualdad de condiciones se encuentra el que contrata un espacio para difundir asuntos religiosos o aspectos culinarios que el que consigue, procesa, selecciona, transmite información y comenta siguiendo todos los elementos metodológicos del periodismo y la comunicación masiva.

Bien sabemos que, en el mundo de hoy, la comunicación ha pasado a ser una gran industria nueva y compleja, por tanto los patrones tecnológicos de hoy imponen a esos medios otras condiciones y compromisos sociales, culturales y educativos que muchas veces no se cumplen.

6.

\section{Medios impresos}

\section{7.}

La población de la República de Panamá se informa y se comunica masivamente desde su configuración como estado a través del medio impreso. Nuestra historia como nación registra numerosos diarios, semanarios, quincenarios que contribuyeron 
a través de sus páginas, a consolidar nuestra integridad como nación y a transmitir en forma constante las ideas y pensamientos de nuestros hombres más ilustres.

Hay que admitir que la prensa escrita ha estado orientada por los patrones clásicos que provienen de Norteamérica, con la diferencia de que además del exceso de mercantilismo que existe en Estados Unidos y que a veces se hace incompatible con los grandes objetivos sociales, en Panamá se ha sumado el interés político y lógicamente de asunción de influencia.

Antes del advenimiento de la televisión, había que reconocer el alto poder de incidencia de los medios escritos y su temible grado de influencia en la vida política panameña. Con la revolución del transistor de radio y con la llegada del televisor, los periódicos han tenido que ir gradualmente ajustando su esfera de influencia y admitiendo una notoria pérdida de mercado.

Actualmente se editan en Panamá, de manera formal, cuatro periódicos tipo estándar, siendo ellos La Prensa, La Estrella de Panamá, El Panama America, El Universal y dos periódicos tipo tabloide La Crítica y El Siglo.

Para todos los panameños, 1968 representa una etapa que se fija en el calendario histórico de nuestro país de manera contundente. El diarismo nacional representa igualmente cambios sustanciales. La periodista y catedrática universitaria panameña ya fallecida, Mélida Sepúlveda al referirse a 1968 y su relación con la legislación de prensa dice: "En 1968, un golpe militar establece un nuevo orden en el país. El curso de la historia se modifica"

En efecto, desde ese momento se inicia la expedición y derogación de normas y leyes relacionadas con la emisión de medios. En este sentido, numerosos países han desarrollado políticas legislativas, estableciendo reglas, normas y controles que protegen los intereses públicos, a la vez que orientan a los medios en su compleja tarea. No obstante, hay que admitir que estos controles muchas veces han sido 


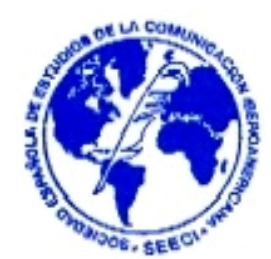

utilizados de manera autoritaria y desmedida, impidiendo el normal desarrollo y función de un medio de comunicación. Este tema, representa todavía un tópico que es discutido en diferentes foros con diferentes posturas. Por un lado, hay quienes sostienen que los países en desarrollo deben señalar pautas en el comportamiento de los medios. Oros, que la aplicación de leyes de prensa obstaculiza incuestionablemente la labor que los medios de comunicación deben cumplir en toda sociedad. Lo cierto es que muchas legislaciones de diversos países latinoamericanos son fieles ejemplos de que, si se tiene un balance equilibrado y armonioso entre la empresa privada y el sector público, así como el personal que interactúa en los propios medios, se puede lograr un avance sustancial en esta materia.

\section{La televisión}

La década de 1950 es considerada por muchos como la época de oro de la televisión norteamericana. Es precisamente a mediados de los cincuenta, cuando el Departamento de Defensa de Estados Unidos de Norteamérica establece, en el año 1956, el primer canal de televisión de la República de Panamá para que sirviera como vehículo informativo y de entretenimiento del cuerpo de soldados y civiles residentes en el sector, de la entonces llamada, Zona del Canal de Panamá. Por razones de los compromisos adquiridos por nuestro país en los diferentes acuerdos canaleros, Panamá se vio precisada a otorgar el uso de dos canales de televisión, el 8 y el 10, en la banda VHF a las Fuerzas Armadas de los Estados Unidos. Los Tratados Torrijos Carter refrendan el uso de redes de comunicación e instalaciones electrónicas dentro de las áreas de funcionamiento del canal, así como las frecuencias de radio autorizadas con anterioridad.

El hecho de que en Panamá existía un sistema de televisión extranjero, obliga a nuestro país a recabar, de países como México, los elementos más esenciales que le permitieran elaborar un documento en extremo general, pero que sirviera para futuras acciones referentes a este medio de comunicación. Es así como la Asamblea 


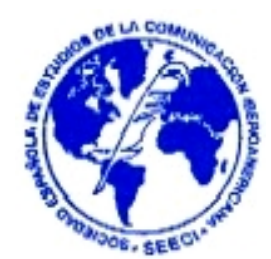

aprueba el Decreto Ley Número 16 del 16 de agosto de 1956, por el cual se toman medidas relacionadas con el establecimiento y funcionamiento de la televisión en la república. Este decreto es reemplazado con el decreto 10 de 1959. De allí, el 14 de marzo de 1960, los hermanos Eleta inauguran la primera planta televisiva comercial RPC, Canal 4. Luego, en 1962, la familia Chiari inaugura la segunda, Televisora Nacional Canal 2.

Inicialmente, siendo estos dos canales los únicos con programación en español y nacional, se enfocan en la transmisión de enlatados norteamericanos traducidos al español.

El desarrollo tecnológico de la televisión panameña ha sido impresionante. En pocos años se produjeron sustanciales cambios técnicos. Por ejemplo, el uso de unidades móviles, transmisiones en vivo, incorporación del color, transmisiones vía satélite, eventos noticiosos, deportivos, culturales y todos los últimos adelantos que en materia de televisión emergen en el mundo han sido puestos en marcha en Panamá.

En la actualidad existen en Panamá cinco canales de televisión: Televisora Nacional, S. A. Canal Dos, Corporación Medios de Comunicación, S. A. (MEDCOM, S.A.) que agrupa a Canal Cuatro y Canal 13, Canal Cinco FTV, Fundación de televisión Educativa, FETV, Canal Once Sistema de Televisión Educativa solventada por el gobierno nacional a través del Ministerio de Educación y la Universidad de Panamá.

Con respecto a la programación que presentan los canales de televisión en Panamá, podríamos señalar que la misma está basada en los contenidos que rigen a la televisión norteamericana. Este hecho guarda estrecha relación con la dependencia económica y tecnológica que Panamá, al igual que el resto de América Latina, mantiene con los grandes centros de producción y los medios de comunicación. 


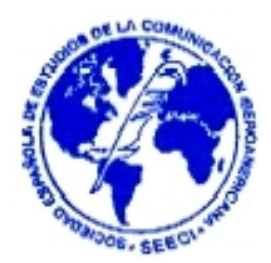

En la televisión panameña, los modelos de programación tienen su base en la televisión norteamericana. Los materiales que se transmiten, comúnmente llamados "enlatados" Ilegan en videocasetes, o son transmitidos vía satélite siempre y cuando sean comerciales y halagadores para las agencias de publicidad.

En relación a la producción local, existen muy pocos programas producidos en Panamá, incluyendo los noticieros y en algunas ocasiones programas en vivo que, por lo general, siguen modelos de la televisión norteamericana. Si observásemos la programación de los tres canales comerciales, Canal 2, Canal 4 y Canal 13, nos atreveríamos a afirmar que su producción semanal está formada por casi un 80 por ciento de programas enlatados, incluyéndose en ese porcentaje, telenovelas realizadas en México, Venezuela, así como películas o series provenientes de Estados Unidos. Esto tiene el propósito de balancear costos de operación, obteniendo una rentabilidad óptima en todo el sentido de la palabra. También influye el ingrediente "rating" concepto impuesto por la publicidad, el cual se puede definir en términos de audiencia y sintonía: mientras mayor sea el número de aparatos de televisión encendidos en un mismo canal, sintonizando igual programa; mayor será el "rating" del canal y del programa y mayor costo representará la pauta de un anuncio comercial determinado. Esto produce que la televisión sea vista como un negocio.

Este negocio establece también costos muy altos para la producción de programas locales. He aquí uno de los inconvenientes para la producción nacional.

En relación a la televisión educativa, al igual que en Estados Unidos y otros países, ésta se debate en forma angustiosa compitiendo con las cadenas comerciales en forma desventurada, sin fuentes de ingreso, sin cobertura significativa a nivel nacional y sin un patrón definido que permita establecer qué es y hacía dónde va en nuestro complejo sistema comunicacional. Sin embargo, aún así, valientemente 
existen en Panamá dos canales de televisión educativos, mismos que no pueden cumplir sus reales objetivos por una falta de recursos económicos bien definidos.

\section{Sistema de televisión por cable}

El Sistema de Cable, conocido también como antena de televisión comunitaria o televisión de pago, ha ido ampliando en Panamá su campo de acción y diversificando su uso a tal punto de que, en los hogares panameños con alto y medio poder adquisitivo, alrededor del $80 \%$ tienen contratados los servicios de televisión por cable de diversas empresas proveedoras, o ubican una parabólica en su residencia.

\section{El cine}

No hay duda de que Estados Unidos, desde sus inicios, ha dominado la industria cinematográfica. Sin embargo, en los últimos años muchos otros países han desarrollado exitosamente esta industria; tal es el caso de la India, la Federación Rusa, Francia, España e inclusive algunos países latinoamericanos como Brasil, Cuba y Argentina.

El cine en Panamá es un gran entretenimiento para el gran público y negocio para las casas productoras peliculeras y empresas de exhibición.

El cine como medio de expresión y divulgación, como testimonio de nuestra realidad y de nuestra cultura, como instrumento impecable para la educación colectiva, no ha tenido jamás el apoyo necesario a excepción de algunos esfuerzos del Grupo Experimental de Cine Universitario GECU y, en otrora, la empresa CINELSA. Para nosotros los panameños, el cine ha servido para que conozcamos los grandes valores culturales de Estados Unidos principalmente, luego de Italia, Inglaterra, Francia, pero 
no ha podido ser vehículo de transporte a esas regiones de nuestra cultura y nuestra realidad.

Uno de los pocos elementos jurídicos para normalizar este instrumento es la creación de la Junta Nacional de Censura, entidad que tiene a su cargo la clasificación de películas. A pesar de que en numerosas ocasiones, especialistas y organizaciones en la materia han planteado la necesidad de que el Estado reglamente los asuntos concernientes al cine en Panamá, no ha sido posible lograr que las autoridades tomen conciencia sobre el estado de la industria del cine y sobre la necesidad de que se configure un centro de material, tal como lo han hecho algunos países del área muy exitosamente.

Es cierto que los medios reflejan la filosofía social y política de los países donde ellos operan y en Panamá este concepto esta bien definido. De ahí que tengamos que admitir que los medios de comunicación, en su mayoría, están orientados por los modelos clásicos que promueve el sistema transnacional y que tienen su base en el país vecino del norte: Estados Unidos. El exceso de mercantilismo existente en ese país es incompatible con los grandes objetivos sociales y políticos de Panamá. Sin embargo, tenemos fe en el futuro; tenemos fe en una nueva generación de hombres y mujeres que se están formando y que tendrán que aportar su intelecto y su trabajo para que, desde muy temprano en el nuevo milenio que se aviene, se desarrolle una nueva comunicación, una comunicación basada en objetivos reales y con ánimos de producir cambios sustanciales en la sociedad panameña que nos lleve hacía la consolidación de una verdadera nación. Una comunicación con compromiso y por ende con medios de comunicación trabajando para el presente y el futuro de manera más crítica y responsable. 